\title{
Interaction effects between dynamic hybrid products and traditional deferred annuities in the German life insurance market
}

\author{
Nikolaj Moretti ${ }^{1}$. Johannes Bartels ${ }^{2}$
}

Published online: 1 February 2021

(C) The Author(s) 2021

\begin{abstract}
Dynamic hybrid products emerged in 2007 and are now well established in the German life insurance market. In this article, we study interaction effects between dynamic hybrid products and traditional deferred annuity contracts, that are sold by the same insurance company. The key question we investigate is whether the presence of dynamic hybrid products has a negative effect on the payout of traditional insurance products. We do so by using data drawn from a Monte Carlo simulation that is based on a model presented in this article. These data reveal that dynamic hybrid products reduce the payment to policyholders of traditional deferred annuities via the channel of surplus participation.
\end{abstract}

Keywords Life insurance - Guaranteed interest rates · Dynamic hybrid · Constant proportion portfolio insurance $\cdot$ Customer value $\cdot$ DTH product $\cdot$ Insurance regulation

JEL Classification G18 · G22

\section{Abbreviations}

AV Account value

DHP Dynamic hybrid product

\footnotetext{
Johannes Bartels: The author works for the Federal Financial Supervisory Authority (BaFin) and as a part-time lecturer at the university of Heidelberg. Every statement, in particular every statement which could be perceived as judgmental, reflects exclusively the opinion of the authors and does not represent the opinion of BaFin.
}

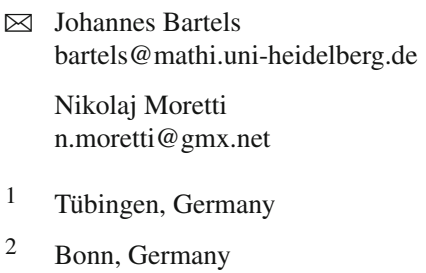


DeckRV Deckungsrückstellungsverordnung (Regulation on the Principles Underlying the Calculation of the Premium Reserve)

EF Equity fund

EqC Equity capital

FOCB First-order calculation bases

GB Guaranteed benefit

GBM Geometric Brownian motion

GF Guarantee fund

KStG Körperschaftssteuergesetz (Corporation Tax Act)

MindZV Mindestzuführungsverordnung (Minimum Allocation Decree)

NIS Net interest surplus

NRR Net risk result

PPR Provisions for premium refunds

PR Policy reserve

SOCB Second-order calculation bases

SP Single premium

TDA Traditional deferred annuity

VAG Versicherungsaufsichtsgesetz (Insurance Supervision Act)

VVG Versicherungsvertragsgesetz (Insurance Contract Act)

\section{Introduction}

In 2007, the German insurance companies LV 1871 and Nürnberger introduced a new class of insurance products on the German life insurance market: dynamic hybrid products (DHPs). DHPs are insurance products that promise to combine the security of a traditional life insurance product with the upward potential of an equity fund. By 2013, more than 20 German insurers offered products classified as dynamic hybrids by Bohnert (2013). More recently, Hambardzumyan and Korn (2019) analyse DHP noting insurers' search for investment opportunities in a low interest rate environment, thus illustrating the relevance of the topic today. In an article published in the German journal Der Aktuar, Menzel (2008) raises the question of whether holders of conventional life insurance products, hereafter referred to as traditional deferred annuities (TDA), are worse off when their contractual partner sells DHP to other customers. He argues that DHP holders can be viewed as obtaining a receiver swaption from the TDA holders without paying for it. Consequently, Menzel expects reductions with respect to the surplus participation for the TDA holders. His point of view is not universally accepted. In the subsequent edition of the same journal, Siebert (2008) criticises Menzel for omitting a number of scenarios from his considerations that would mitigate if not reverse the interaction effects. In this paper, we shed light on the existence of interaction effects to the detriment of TDA holders and quantify them. To this end, we model an insurance company selling both TDA and DHP policies and compare different scenarios in a Monte Carlo simulation. The rest of the paper is structured as follows: a literature review is presented in Sect. 2. Section 3 provides some basic information about DHP and the interaction channel. The model framework of our anal- 
ysis and the numerical results are presented in Sects. 4 and 5, respectively. Section 6 concludes.

\section{Literature review}

The literature offers some qualitative analyses and descriptions as well as quantitative analyses through simulations studies. The functioning of a DHP as well as risks for insurers is explained by Bettels et al. (2011). The contribution by Gatzert and Schmeiser (2013) about new life insurance financial products helps to set DHP in a broader context. An overview of the German market of dynamic hybrid products as of 2013 is given by Bohnert (2013) who lists the main features of DHP sold by more than 20 German insurers. A model framework for a three-pot DHP is proposed by Kochanski and Karnarski (2011). The authors implement a partial internal model for the solvency capital requirements according to the European Solvency II directive. In a more recent article, Hambardzumyan and Korn (2019) solve the optimal portfolio problem related to a particular class of DHP. The question of possible interaction effects between DHP and TDA is raised by Menzel (2008) and Siebert (2008), both coming to different conclusions. Bohnert and Gatzert (2014) as well as Bohnert et al. (2014) use Monte Carlo simulations to study interaction effects arising through the presence of DHP, effects that involve fair valuation, risk analysis, and the policyholders' willingness to pay. This paper contributes to the literature by continuing the investigation begun by Menzel (2008) and Siebert (2008) using a Monte Carlo simulation. Thus, we present insight on the mechanism and magnitude of the interaction effect between DHP and TDA. Our model framework is inspired by Bohnert and Gatzert (2014) and relies on elements proposed by Kochanski and Karnarski (2011). However, our model is more detailed when it comes to calculating the inflows to the PPR and the bonuses distributed to policyholders.

\section{Insurance policies and interaction channel}

\subsection{Insurance policies}

We define a traditional deferred annuity as a textbook insurance policy that promises the policyholder a lump-sum payment at contract termination in case of survival in exchange for a single premium paid at contract start. ${ }^{1}$ The lump-sum payment depends on the actuarial interest rate the insurer promises to the policyholder and the number of deaths among the policyholder cohort during the contract duration. A dynamic hybrid product is an insurance policy designed to combine potentially higher returns of investments in equity funds with a certain degree of security required by policyholders. This is achieved by a dynamic investment strategy that shifts money between different investment options. These "pots" are generally the insurer's policy reserve (PR) and one or two equity funds. The dynamic aspect of the product is its periodic monitoring

\footnotetext{
1 Compare with what Gatzert and Schmeiser (2013) call traditional participating life insurance and what Ortmann (2009, Ch. 4.3) calls "Einmalige Erlebensfallleistung”.
} 


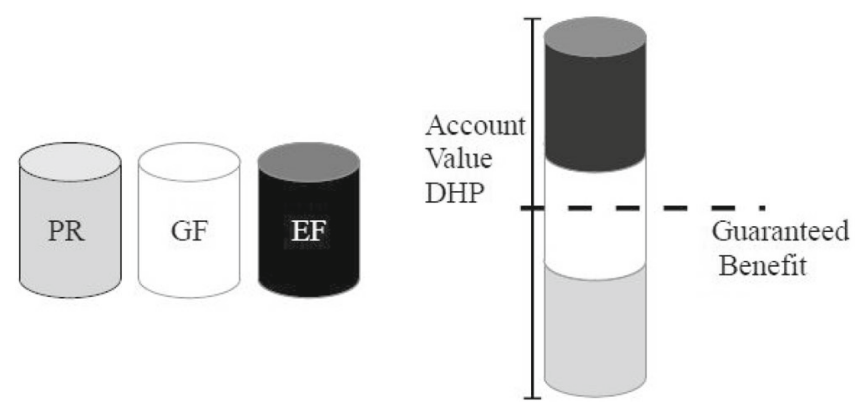

Fig. 1 Diagram of a DHP and its single components
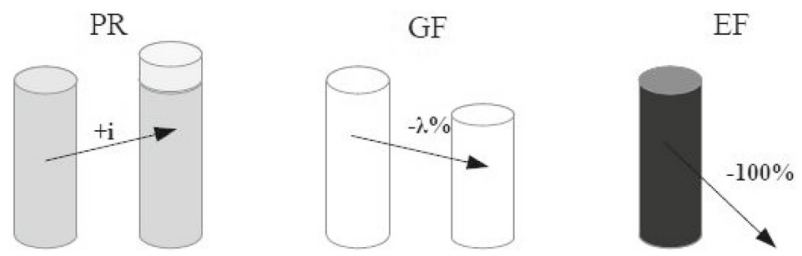

Fig. 2 Worst-case development of the DHP pots from period $t$ to $t+1$

and reallocation between the pots. Ideally, the insurer invests the money in risky equity funds in order to generate higher returns and shifts money to the PR as soon as the guaranteed insurance benefit is endangered by an adverse market development, at which point the money is "parked" in the insurer's policy reserve, where the money of the TDA is invested. The term "parked" is chosen deliberately to emphasise that the money is taking shelter for a short term and only waiting to be reinvested in riskier assets in order to generate higher returns. A DHP could be structured as represented in Fig. 1.

For this exemplary product, the policyholder's money is split and allocated to three pots: the insurer's PR, a guarantee fund (GF) with a downside protection that limits losses from 1 month to the next to $\lambda \%$ (e.g. through short-term put options on the assets the GF is based on), and an equity fund (EF) with no protection and without the hedging costs of the GF. A worst case scenario for the single DHP components from 1 month to the next is shown in Fig. 2.

The money allocated to the PR is subject to the actuarial interest rate $i_{G} . i_{G}$ corresponds to the maximal interest rate allowed to discount future benefits of contracts stemming from a specific underwriting period. The insurer takes on the risk associated with the investment of the money-just as he does with the money of the TDA policyholders. However, the risk of investment in the GF and EF is borne by the DHP policyholders. Therefore, the worst case scenario for the money allocated to the GF is a loss of $\lambda \%$, due to the downside protection. For the EF, the worst case scenario is a total loss of the money allocated to it. The upside of this arrangement is that the totality of profits goes to the policyholder in the event the two funds develop well. 


\subsection{The interaction channel}

The German life insurance market is regulated in the interest of making it a safe investment for consumers. Art.5 $§ 1$ of the "Deckungsrückstellungsverordnung" (DeckRV) (Regulation on the Principles Underlying the Calculation of the Premium Reserve) requires the insurer to employ prudent estimates of death and interest rates as well as future costs, especially when calculating the PR; Art.138 of the "Versicherungsaufsichtsgesetz" (VAG) (Insurance Supervision Act) requires the insurer to set premiums sufficiently high to cover resulting liabilities. The so-called first-order calculation bases (FOCB), necessary to comply with Art.5 $\$ 1$ DeckRV, include a safety margin (as opposed to the so-called second-order calculation bases (SOCB) which do not). In general, calculations based on the FOCB entail premiums for the single insurance policies that are higher than what is actually needed for the promised payout. Insurers are thus forced by law to have a surplus at the end of each year. Art.153 $\$ 1$ "Versicherungsvertragsgesetz" (VVG) (Insurance Contract Act) grants policyholders a legal claim to surplus participation. This participation usually occurs in two ways: first, through direct credits, or second, through the so-called provision for premium refunds (PPR). Since direct credits played only a subordinate role when DHPs were introduced in $2007,{ }^{2}$ we focus on the PPR. The PPR is a liability item in the insurer's economic balance sheet conceived to smooth potential fluctuations in surpluses over the years. It does so by allowing different in- and outflows to it in the same year. For example, in years with lower surpluses, the outflows will generally be higher than the inflows and vice versa. ${ }^{3}$ The inflows are thereby a function of the surpluses, and the outflows are the bonuses allocated to the policyholders. For the insurer, the PPR is a useful cushion in times of sinking long-term asset returns. In contrast to the PR, a liability item that grows with the actuarial interest rate $i_{G}$, the PPR only grows with inflows stemming from surpluses. Therefore, the insurer has an interest in keeping as much as possible in the PPR when interest rates and profits decrease. However, the insurer is not allowed to stock money in the PPR infinitely. ${ }^{4}$ Hence, bonuses are allocated to the policyholders, generally with a delay of a few years. The different approaches employed for distributing bonuses are described by Führer and Grimmer (2010, pp. 160-161). One option common for pension insurances with a single upfront premium is to treat the bonuses like additional single premiums the policyholder invests in new insurance policies with the same range of services and date of maturity as the original contract, thus increasing the policyholder's lump-sum payment at the end of contract. We use this way of allocating bonuses in our model framework. We now explain how the first interaction effect between TDA and DHP takes place when the insurer calculates the inflows to the PPR. The second interaction takes place when it determines the outflows from the PPR.

\footnotetext{
2 See Führer and Grimmer (2010, p. 156).

3 See Führer and Grimmer (2010, Ch. F.2.3.1).

4 Art.34 §8.1 "Körperschaftssteuergesetz" (KStG) (Corporation Tax Act) in conjunction with Art.21 2 KStG states that the PPR should not contain more than the sum of the inflows to the PPR of the five last years. Note that this last provision was superseded on 1 January 2019. In our model, we take into account the law in its previous form.
} 
Table 1 Sources of total profits made by German life insurers in per cent. Source: Primary insurers' statistics by the Federal Financial Supervisory Authority (Erstversicherungsstatistik der BaFin)

\begin{tabular}{lccllll}
\hline & $2005(\%)$ & $2006(\%)$ & $2007(\%)$ & $2016(\%)$ & $2017(\%)$ & $2018(\%)$ \\
\hline Risk result & 34.5 & 37.0 & 38.8 & 61.3 & 58.9 & 54.5 \\
Interest surplus & 73.9 & 65.6 & 62.0 & 32.9 & 33.3 & 43.8 \\
Residual result & -8.4 & -2.6 & -0.8 & 5.8 & 7.8 & 1.7 \\
\hline
\end{tabular}

\subsubsection{Inflows to the PPR}

In general, four main sources of inflows to the PPR can be distinguished: the risk result, the interest surplus, the cost result, and the residual result. Simply put, the risk result derives from the deviation of the expected (assumed) mortality from the actual one and corresponds to the surpluses/losses caused by this deviation. The interest surplus emanates from the difference between the interest gains promised to the policyholders (the actuarial interest rate) and the insurer's actual investment profits. The cost result is the difference between expected and actual costs for the insurer and the residual value includes other parts of the insurer's economic activity (e.g. reinsurance). Table 1 shows the proportion of the different sources for the years 2005-2007 and 2016-2018 for German life insurers.

For the sake of simplicity and since they constitute the lion's share of the total result, we assume that the inflows to the PPR are calculated based only on the risk result and the interest surplus. Arts.6 and 7 of the "Mindestzuführungsverordnung" (MindZV) (Minimum Allocation Decree) mandate which shares of the risk result and the interest surplus are to be allocated to the PPR. We will denote them as net risk result (NRR) and net interest surplus (NIS). The NRR is calculated separately for different subgroups of policyholders. No interaction between TDA and DHP takes place at this stage. What about the NIS? Let $i_{G}$ denote the actuarial interest rate, $i_{A}^{\text {lt }}\left(i_{A}^{\text {st }}\right)$ denote the returns on long-term (short-term) assets, $A^{\text {lt }}\left(A^{\text {st }}\right)$ the insurer's long-term investments (short-term investments), and PR ${ }^{\mathrm{TDA}}$ ( $\mathrm{PR}^{\mathrm{DHP}}$ ) the part of the insurer's total PR destined for the TDA (DHP). The provisions of Art.6 MindZV about the NIS can be translated into the equation

$$
\mathrm{NIS}=\alpha \cdot\left(i_{A}^{\mathrm{lt}} \cdot \text { Assets }^{\mathrm{lt}}+i_{A}^{\mathrm{st}} \cdot \text { Assets }^{\mathrm{st}}\right) \cdot \beta-i_{G} \cdot\left(\mathrm{PR}^{\mathrm{TDA}}+\mathrm{PR}^{\mathrm{DHP}}\right)
$$

with $\alpha \in\{0.9,1\}$ (see Sect. 4) and $\beta:=\frac{\mathrm{PR}^{\mathrm{TDA}}+\mathrm{PR}^{\mathrm{DHP}}}{\text { Total liabilities }}$ the insurer's policy reserves divided by the insurer's total liabilities. Now, DHP sold by the insurer will directly influence $\mathrm{PR}^{\mathrm{DHP}}$ (if money is allocated from the GF and EF to the insurer's policy reserves) and indirectly affect $\alpha$ and $\beta$. Even if the direction is unknown at this point, it is clear that there will be some kind of effect on NIS. This is the first interaction effect. 


\subsubsection{Outflows from the PPR — distribution of profits to the policyholders}

When calculating the outflows from the PPR for the current period, the insurer must take several legal constraints into account. These considerations will be translated into an algorithm in Sect. 4. For the time being, we assume that the total bonus sum Bonus $^{\text {total }}$ has already been calculated in the current period. To subsequently calculate the bonus shares going to the subgroups of policyholders, we follow the procedure described in Art.5 $\$ 2$ c of a DHP called SIGGI sold by the German insurer Signal Iduna. ${ }^{5}$ Thereby, the bonuses for each subgroup of policyholders correspond to the subgroup's share of the insurer's PR. For the bonuses going to the TDA policyholders, this yields

$$
\text { Bonus }^{\mathrm{TDA}}=\text { Bonus }^{\text {total }} \cdot \frac{\mathrm{PR}^{\mathrm{TDA}}}{\mathrm{PR}^{\mathrm{TDA}}+\mathrm{PR}^{\mathrm{DHP}}} \text {. }
$$

Now an increase of $\mathrm{PR}^{\mathrm{DHP}}$ unequivocally entails a decrease of Bonus ${ }^{\mathrm{TDA}}$. This constitutes the second interaction effect between TDA and DHP policies.

\section{Model}

\subsection{Model framework}

In the following section, we describe the insurance company model. It is inspired by the model used by Bohnert and Gatzert (2014) and uses parts of the modelling strategies proposed by Kochanski and Karnarski (2011). Our contribution primarily lies in proposing algorithms for model inflows to the PPR and for the bonus distribution, two mechanisms not included in previous models but constituting the aforementioned interaction effect. The observed time periods will be $t \epsilon\{0, \ldots, T\}, T=12 \cdot n+1$, where $n$ is the contract duration of the policies sold by the insurer. For our standard contract duration of 30 years, $T=361$, giving one period for each month in the 30 years plus one for the initial values $(t=0)$ and one for the final values $(t=361)$. Let $Y:=\{t=12 \cdot i \mid i \epsilon\{1, \ldots, n\}\} \subset\{0, \ldots, T\}$ denote the set of end-of-year periods. This will come in handy since some variables change only at the end of a year. The balance sheet of the insurer is illustrated in Table 2 .

On the asset side of the balance sheet, we have assets that are long-term investments $A^{\text {lt }}$ and others that are invested short term $A^{\text {st }}$. We further see the items $\mathrm{GF}^{A}$ and $\mathrm{EF}^{A}$ standing for investment in the DHP's guarantee and equity funds. Since the policyholders bear the risk for the investment in the GF and EF, they are always equivalent to their counterparts on the liability side $\mathrm{GF}^{L}$ and $\mathrm{EF}^{L}$. On the liability side, we find the insurer's policy reserves PR, split between those "belonging" to the two subgroups of policyholders. The provisions for premium refunds PPR and the equity capital EC complete the insurer's liabilities. The EC is artificially split into a

\footnotetext{
5 See product description available at https://www.signal-iduna.de/media/10612_2352007_Jan17.pdf (accessed: 26.04.2020).
} 
Table 2 Economic balance sheet

\begin{tabular}{ll}
\hline Assets & Liabilities \\
\hline$A^{\mathrm{lt}}$ & $\mathrm{PR}^{\mathrm{TDA}}$ \\
$A^{\mathrm{st}}$ & $\mathrm{PR}^{\mathrm{DHP}}$ \\
$\mathrm{GF}^{A}$ & $\mathrm{GF}^{L}$ \\
$\mathrm{EF}^{A}$ & $\mathrm{EF}^{L}$ \\
& $\mathrm{PPR}^{\mathrm{PP}}$ \\
& $\mathrm{EC}^{\mathrm{lt}}$ \\
& $\mathrm{EC}^{\mathrm{st}}$ \\
\hline
\end{tabular}

Table 3 Model variables

\begin{tabular}{ll}
\hline$A_{t}^{\mathrm{lt}}$ & Assets long term \\
$A_{t}^{\mathrm{st}}$ & Assets short term \\
$\mathrm{PR}_{t}^{\mathrm{TDA}}$ & Policy reserves TDA \\
$\mathrm{PR}_{t}^{\mathrm{DHP}}$ & Policy reserves DHP \\
$\mathrm{GF}_{t}$ & Guarantee fund \\
$\mathrm{EF}_{t}$ & Equity fund \\
$G_{t}$ & Risk free guarantee amount DHP (see Kochanski and Karnarski 2011) \\
$\mathrm{PPR}_{t}$ & Provisions for premium refunds \\
$\mathrm{EC}^{\mathrm{lt}}$ & Equity capital invested long term \\
$\mathrm{EC}_{t}^{\mathrm{st}}$ & Equity capital invested short term (liquidity cushion) \\
$\mathrm{LSP}_{t}$ & Lump-sum payment TDA at contract termination \\
$\mathrm{NIS}_{t}$ & Net interest surplus \\
$\mathrm{RR}_{t}^{\mathrm{TDA}}$ & Risk result TDA \\
$\mathrm{AV}_{t}$ & Account value of a single DHP contract \\
$\mathrm{Bonus}_{t}^{\mathrm{TDA}}$ & Bonus payment allocated to TDA policyholders \\
$\mathrm{Bonus}_{t}^{\mathrm{DHP}}$ & Bonus payment allocated to DHP policyholders \\
$\mathrm{Inflows}_{t}^{\mathrm{PPR}}$ & Inflows to the provisions for premium refunds \\
$L_{t}^{\mathrm{TDA}}$ & Number of living TDA policyholders \\
$\mathcal{E}_{t-1}\left[L_{t}^{\mathrm{TDA}}\right]$ & Expected number of living TDA policyholders \\
$L_{t}^{\mathrm{DHP}}$ & Number of living DHP policyholders \\
\hline & \\
\hline & \\
&
\end{tabular}

part that is invested in long-term assets $\left(\mathrm{EC}^{\mathrm{lt}}\right)$ and a liquidity cushion $\left(\mathrm{EC}^{\mathrm{st}}\right)$. Table 3 enumerates the variables used in the model.

The number of living policyholders for $j \epsilon\{$ TDA, DHP $\}$ is assumed to evolve in the following way:

$$
L_{t}^{j}=\left\lfloor L_{t-1}^{j} \cdot\left(l_{x+\lfloor t / 12\rfloor}^{\mathrm{SOCB}}\right)\left(l_{x+\lfloor(t-1) / 12\rfloor}^{\mathrm{SOCB}}\right)^{-1}\right\rfloor
$$


where $l_{m}^{\text {SOCB }}$ are second-order calculation bases for the number of $m$ year old men taken from the mortality table DAV2004R (without the security-margin imposed by law). ${ }^{6}$ We assume that each policyholder buys only one contract. The number of expected living (i.e. the number used by the insurer in period $t-1$ to calculate their policy reserves in period $t$ ) is assumed to evolve as follows:

$$
\mathcal{E}_{t-1}\left[L_{t}^{\mathrm{TDA}}\right]=L_{t-1}^{\mathrm{TDA}} \cdot\left(l_{x+\lfloor t / 12\rfloor}^{\mathrm{FOCB}}\right)\left(l_{x+\lfloor(t-1) / 12\rfloor}^{\mathrm{FOCB}}\right)^{-1}
$$

where $l_{m}^{\text {FOCB }}$ are first-order calculation bases for the number of $m$-year-old men taken from the mortality table DAV2004R (with security margin). Note that we do not calculate this variable for DHP since we assume this product to pay a death benefit. ${ }^{7}$ A measure closely connected to the calculation bases and used at later points is the so-called number of discounted living at age $\mathrm{m} D_{m} \cdot{ }^{8}$ It is defined as

$$
D_{m}:=l_{m}^{\mathrm{FOCB}} \cdot\left(1+i_{G}\right)^{-m} .
$$

The TDA's “temporary final payout", assumed to occur as lump-sum payment LSP, is given by

$$
\mathrm{LSP}_{0}=\mathrm{SP} \cdot \frac{D_{h}}{D_{h+n}} \text { for } t \epsilon Y
$$

where SP denotes the single premium paid up front by policyholders, $h$ the policyholder's age at the conclusion of contract, and $n$ the contract duration in years. Note that, in general, $\mathrm{LSP}_{t}$ denotes the expected payout at contract termination, disregarding bonus participation occurring after period $t$. It does not denote a payment occurring in period $t$. Let us now consider the development of the balance sheet items.

The transition mechanism of the long-term assets is given by

$$
A_{t}^{\mathrm{lt}}=A_{t-1}^{\mathrm{lt}} \cdot \sqrt[12]{\left(1+i_{A}^{\mathrm{lt}}\right)} .
$$

The short-term assets are calculated as the sum of the policy reserves and the equity capital invested short term. Since the short-term interest rate is zero, the development of short-term assets is given by

$$
A_{t}^{\mathrm{st}}=\mathrm{PR}_{t}^{\mathrm{DHP}}+\mathrm{EC}_{t}^{\mathrm{st}} \text {. }
$$

\footnotetext{
6 Note that since December 2012, pricing in Germany has not been allowed to be based on gender. The mortality table for men is used for illustration purpose.

7 Most DHP products on the German market include a death benefit for the policyholder that at least amounts to the account value of the DHP at the time of death (e.g. Genius (Württembergische), SIGGI (Signal Iduna), Garantierente Zukunft (Die Bayerische), Alfonds (Alte Leipziger)). Bohnert (2013) enumerates only three insurers that offered a "no death benefit" option in 2013.

8 See Ortmann (2009, p. 125).
} 
The development of the PR is given through

$$
\begin{aligned}
\mathrm{PR}_{t}^{\mathrm{DHP}} & =\mathrm{PR}_{t-1}^{\mathrm{DHP}} \cdot \sqrt[12]{1+i_{G}} \\
\mathrm{PR}_{t}^{\mathrm{TDA}} & = \begin{cases}\mathrm{PR}_{t-1}^{\mathrm{TDA}} \cdot \sqrt[12]{1+i_{G}} \cdot \gamma_{t}^{\mathrm{TDA}} & \text { for } t \in Y \\
\mathrm{PR}_{t-1}^{\mathrm{TDA}} \cdot \sqrt[12]{1+i_{G}} & \text { otherwise }\end{cases}
\end{aligned}
$$

where multiplication with $\gamma_{t}^{\mathrm{TDA}}:=L_{t}^{\mathrm{TDA}} \cdot\left(L_{t-1}^{\mathrm{TDA}}\right)^{-1}$ reduces policy reserves to the amount needed to ensure payout for the remaining contracts. (Note that the risk result is taken into account in the bonus section and that for the DHP's funds in the policy reserve, deaths are taken into account in the management decision in Eq. (19).)

If $\mathrm{PR}_{t}^{\mathrm{DHP}}>0$, this liability item grows with the guaranteed interest rate $i_{G}$. Thus, should funds be shifted back from the $\mathrm{PR}^{\mathrm{DHP}}$ to the GF or EF, more funds need to be shifted back than what was taken earlier. Hence, the insurer needs assets that may be liquidated when this reallocation occurs. To take this into account, a growth through interest gains of the $\mathrm{PR}^{\mathrm{DHP}}$ goes hand in hand with an equivalent decrease of $\mathrm{EC}^{\mathrm{st}}$. Turning our attention to the development of $\mathrm{EC}^{\mathrm{st}}$, note that for $t \epsilon Y, \mathrm{SP}^{\mathrm{DHP}}$ the single premium paid by DHP policyholders, and $x \cdot \mathrm{SP}^{\mathrm{DHP}}$ the guaranteed benefit at the end of the contract term of the DHP, the amount of short-term liquidity needed to cover the DHPs' interest gains is bound by the interest gains a single DHP policy would realise in the last year of contract term if all its funds were shifted to the insurer's policy reserve (in that event, the DHP would pay only its guaranteed benefit and the interest gains would be smaller than $i_{G} \cdot x \cdot \mathrm{SP}_{\mathrm{DHP}}$ ) multiplied by the current number of DHP policies held by the insurer at the beginning of the previous year $\left(L_{t-12}^{\mathrm{DHP}}\right)$, giving the rough estimation of maximum liquidity needed

$$
\mathrm{EC}_{t}^{\mathrm{st}}-\mathrm{EC}_{t-12}^{\mathrm{st}} \leq i_{G} \cdot x \cdot \mathrm{SP}^{\mathrm{DHP}} \cdot L_{t-12}^{\mathrm{DHP}} .
$$

For the sake of simplicity, we assume that the insurer makes its investment decisions at the beginning of each year and ensures that the liquidity cushion contains this amount.

$$
\mathrm{EC}_{t}^{\mathrm{st}}= \begin{cases}i_{G} \cdot x \cdot \mathrm{SP}_{\mathrm{DHP}} \cdot L_{t}^{\mathrm{DHP}} & \text { for } t \epsilon Y \\ \mathrm{EC}_{t-1}^{\mathrm{st}}-\mathrm{PR}_{t-1}^{\mathrm{DHP}} \cdot \sqrt[12]{1+i_{G}} & \text { otherwise. }\end{cases}
$$

If the insurer needs to add money to the liquidity buffer, it does so by liquidating long-term assets at a cost $\Theta \geq 0$. If the buffer exceeds the needed amount, the surplus is invested in long-term assets. Furthermore, a dividend $\delta$ as percentage of the equity capital is paid out to the shareholders. The long-term assets are thus adjusted in each period $t \in Y$ to

$$
\begin{aligned}
A_{t}^{\mathrm{lt}}= & A_{t}^{\mathrm{lt}}-\max \left[(1+\Theta) \cdot\left(\mathrm{EC}_{t}^{\mathrm{st}}-\mathrm{EC}_{t-1}^{\mathrm{st}}\right), \mathrm{EC}_{t}^{\mathrm{st}}-\mathrm{EC}_{t-1}^{\mathrm{st}}\right] \\
& -\delta\left(\mathrm{EC}_{t}^{\mathrm{st}}+\mathrm{EC}_{t}^{\mathrm{lt}}\right) .
\end{aligned}
$$


The GF and EF are assumed to evolve following two GBMs, given by the stochastic differential equations

$$
\frac{\mathrm{d} S^{\mathrm{GF}}(t)}{S^{\mathrm{GF}}(t)}=\mu^{\mathrm{GF}} \cdot \mathrm{d} t+\sigma^{\mathrm{GF}} \cdot \mathrm{d} W^{\mathrm{GF}}(t)
$$

for the GF and

$$
\frac{\mathrm{d} S^{\mathrm{EF}}(t)}{S^{\mathrm{EF}}(t)}=\mu^{\mathrm{EF}} \cdot \mathrm{d} t+\sigma^{\mathrm{EF}} \cdot \mathrm{d} W^{\mathrm{EF}}(t)
$$

for the EF, with constant drift coefficient $\mu^{i}$, volatility coefficient $\sigma^{i}$, two Wiener processes $W^{i}(t)$ with correlation $\rho$, and initial value $S^{i}(0)=1, i \epsilon\{\mathrm{GF}, \mathrm{EF}\}$. Inspired by Kochanski and Karnarski (2011), the development of the GF and the EF is given by

$$
\mathrm{GF}_{t}^{A}=\mathrm{GF}_{t-1}^{A} \cdot \max \left(1-\lambda, \frac{S_{t}^{\mathrm{GF}}}{S_{t-1}^{\mathrm{GF}}+P_{t-1,1 / 12}^{\mathrm{CP}}} \cdot \sqrt[12]{1-v}\right)
$$

and

$$
\mathrm{EF}_{t}^{A}=\mathrm{EF}_{t-1}^{A} \cdot \frac{S_{t}^{\mathrm{EF}}}{S_{t-1}^{\mathrm{EF}}} \cdot \sqrt[12]{1-v}
$$

where $v$ denotes a yearly management fee, $\lambda$ denotes the maximum loss in per cent that the downside protection of the GF allows, and $P_{t, 1 / 12}^{\mathrm{CP}}$ is a parameter from the Black-Scholes formula for option pricing. ${ }^{9}$ In a second step, the funds of the DHP are reallocated following a management decision $M D\left(\mathrm{AV}_{t}, t\right)$ inspired by Kochanski and Karnarski (2011). We model a product that is monitored on a monthly basis. ${ }^{10}$ The bonus the DHP holders are entitled to is added to the current account value (AV) of the DHP policies before funds are reallocated at the beginning of each period (note that Bonus $_{t}^{\mathrm{DHP}}=0$, for $\left.t \notin Y\right)$ :

$$
\mathrm{AV}_{t}:=\left(\mathrm{PR}_{t}^{\mathrm{DHP}}+\mathrm{GF}_{t}^{L}+\mathrm{EF}_{t}^{L}+\operatorname{Bonus}_{t}^{\mathrm{DHP}}\right) \cdot\left(L_{t}^{\mathrm{DHP}}\right)^{-1}
$$

\footnotetext{
9 See, for example, Hull (2003). We consider call options with a maturity of 1 month $(\Delta t=1 / 12)$ $P_{t, 1 / 12}^{\mathrm{CP}}\left((1-\lambda) S_{t}, t+1\right)=S_{t} \cdot\left((1-\lambda) \Phi\left(-d_{2}\right)-e^{-\frac{1}{12} \log (1-v)} \Phi\left(-d_{1}\right)\right) \quad$ with $d_{1}=\left[\frac{1}{12} \cdot \frac{1}{2}\left(\sigma^{\mathrm{CP}}\right)^{2}-\log (1-\lambda)-\frac{1}{12} \log (1-v)\right] \cdot\left(\sigma^{\mathrm{CP}} \cdot \sqrt[12]{\frac{1}{12}}\right)^{-1} \quad$ and $d_{2}=d_{1}-\sigma^{\mathrm{CP}} \sqrt[12]{\frac{1}{12}}$.

10 Eighteen of the 21 insurers studied by Bohnert (2013) monitor their product on a monthly basis.
} 
The once again aggregated values for $\mathrm{PR}, \mathrm{GF}$, and $\mathrm{EF}$ are

$$
\begin{aligned}
& \mathrm{PR}_{t+1}^{\mathrm{DHP}} \cdot\left(L_{t+1}^{\mathrm{DHP}}\right)^{-1}= \begin{cases}\left(G_{t+1}-(1-\lambda) \cdot \mathrm{AV}_{t+1}\right) \cdot\left(\sqrt[12]{1+i_{G}}-1+\lambda\right)^{-1} & \text { if } \frac{G_{t+1}}{(1-\lambda) \cdot \mathrm{AV}_{t+1}}>1 \\
0 & \text { otherwise }\end{cases} \\
& \mathrm{GF}_{t+1}^{L} \cdot\left(L_{t+1}^{\mathrm{DHP}}\right)^{-1}= \begin{cases}\mathrm{AV}_{t+1}-\mathrm{PR}_{t+1}^{\mathrm{DHP}} & \text { if } \frac{G_{t+1}}{(1-\lambda) \cdot \mathrm{AV}_{t+1}}>1 \\
\frac{G_{t+1}}{1-\lambda} & \text { otherwise }\end{cases} \\
& \mathrm{EF}_{t+1}^{L} \cdot\left(L_{t+1}^{\mathrm{DHP}}\right)^{-1}=\mathrm{AV}_{t+1}-\mathrm{PR}_{t+1}^{\mathrm{DHP}}-\mathrm{GF}_{t+1} .
\end{aligned}
$$

$G_{t}$ is defined as the amount needed in period t to ensure the guaranteed benefit $x \cdot \mathrm{SP}$ DHP via the actuarial interest rate at contract termination

$$
G_{t}=x \cdot \mathrm{SP}^{\mathrm{DHP}} \cdot\left(\frac{1}{1+i_{G}}\right)^{(T-1)-t} .
$$

Dividing by $L_{t}^{\text {DHP }}$ in Eq. (18) and multiplying by $L_{t+1}^{\text {DHP }}$ in Eqs. (19), (20), and (21), we eliminate the death benefit paid out to deceased DHP policyholders. The development of the provision for premium refunds is given by

$$
\mathrm{PPR}_{t}=\mathrm{PPR}_{t-1}+\operatorname{Inflows}_{t}^{\mathrm{PPR}}-\left(\text { Bonus }_{t}^{\mathrm{TDA}}+\text { Bonus }_{t}^{\mathrm{DHP}}\right) .
$$

The insurer's long-term equity capital is given by the residual value

$$
\mathrm{EC}_{t}^{\mathrm{lt}}=A_{t}^{\mathrm{lt}}+A_{t}^{\mathrm{st}}-\mathrm{PR}_{t}^{\mathrm{TDA}}-\mathrm{PR}_{t}^{\mathrm{DHP}}-\mathrm{PPR}_{t}-\mathrm{EC}_{t}^{\mathrm{st}}
$$

Below, special care is given to describing the modelling of inflows to the PPR and the bonus allocation mechanism, the stage of the interaction effect.

\section{Inflows to the PPR}

The inflows to the PPR are given by

$$
\text { Inflows }_{t}^{\mathrm{PPR}}=\max \left(\mathrm{NRR}_{t}^{\mathrm{TDA}}+\mathrm{NIS}_{t}^{\text {yearly }}, 0\right)
$$

for $t \epsilon Y$ and are 0 for $t \notin Y$ (see Art.3 $\$ 2$ MindZV). The NIS is calculated every month based on the provisions of Art.6 $\$ 1$ MindZV. Translated into our framework, the monthly NIS is given by

$$
\begin{aligned}
\operatorname{NIS}_{t}^{\text {monthly }}(\alpha):= & \alpha\left[\left(\sqrt[12]{1+i_{A}^{\mathrm{lt}}}-1\right) \cdot A_{t}^{\mathrm{lt}}+\left(\sqrt[12]{1+i_{A}^{\mathrm{st}}}-1\right) \cdot A_{t}^{\mathrm{st}}\right] \cdot \beta_{t} \\
& -\left(\sqrt[12]{1+i_{G}}-1\right) \cdot\left(\mathrm{PR}_{t}^{\mathrm{TDA}}+\mathrm{PR}_{t}^{\mathrm{DHP}}\right)
\end{aligned}
$$


for $\alpha \epsilon\{0.9,1\}$ (see Eq. (29)). $\beta_{t}$ denotes the weight of the policy reserves to the balance sheet total $\left(=A^{\mathrm{lt}}+A^{\mathrm{st}}\right)$ for the year $y \epsilon Y$, where $y$ is the next bigger (or equal) multiple of 12 of $t, y:=12 \cdot\lceil t / 12\rceil$, defined as

$$
\beta_{t}:=0.5\left(\frac{\mathrm{PR}_{y-12}^{\mathrm{TDA}}+\mathrm{PR}_{y-12}^{\mathrm{DHP}}}{A_{y-12}^{\mathrm{lt}}+A_{y-12}^{\mathrm{st}}}+\frac{\mathrm{PR}_{y}^{\mathrm{TDA}}+\mathrm{PR}_{y}^{\mathrm{DHP}}}{A_{y}^{\mathrm{lt}}+A_{y}^{\mathrm{st}}}\right) .
$$

Define

$$
\operatorname{NIS}_{t}^{\text {yearly }}(\alpha):=\sum_{j=0}^{11} \mathrm{NIS}_{t-j}^{\text {monthly }}(\alpha)
$$

To obtain the yearly NIS, ${ }^{11}$ we distinguish the following cases based on Art.6 MindZV for $t \in Y$

$$
\mathrm{NIS}_{t}^{\text {yearly }}= \begin{cases}\operatorname{NIS}_{t}^{\text {yearly }}(0.9) & \text { for } \operatorname{NIS}_{t}^{\text {yearly }}(0.9)>0 \\ 0 & \text { for } \operatorname{NIS}_{t}^{\text {yearly }}(0.9)<0 \\ & \text { and } \operatorname{NIS}_{t}^{\text {yearly }}(1)>0 \\ \operatorname{NIS}_{t}^{\text {yearly }}(1) & \text { for } \operatorname{NIS}_{t}^{\text {yearly }}(1)<0\end{cases}
$$

The risk result NRR is calculated at the end of the year for the TDA policyholders. According to Art.7 MindZV, the net risk result (NRR) of the TDA is given by

$$
\mathrm{NRR}_{t}^{\mathrm{TDA}}:=\max \left(0,0.9 \cdot \mathrm{PR}_{t-1}^{\mathrm{TDA}} \cdot \frac{\mathcal{E}_{t-1}\left[L_{t}^{\mathrm{TDA}}\right]-L_{t}^{\mathrm{TDA}}}{L_{t-1}^{\mathrm{TDA}}}\right)
$$

for $t \epsilon Y$ and by $\mathrm{NRR}_{t}^{\mathrm{TDA}}:=0$ for all other $t$. In contrast, it is assumed that the DHP includes a death benefit amounting to its current account value and will consequently not generate any risk result. ${ }^{12}$

\section{Bonuses}

We now consider the allocation of bonuses, the second core alteration our model introduces. We included an allocation algorithm we believe captures the essential features of real-world bonus allocation. It is based on the following considerations: German law clarifies that the money in the PPR can be used only for premium refunds ${ }^{13}$

\footnotetext{
${ }^{11}$ Even though most DHPs are monitored on a monthly basis, German law requires the NIS to be calculated on a yearly basis. See, for instance, the DHP SIGGI sold by Signal Iduna. See Art.5 §2, c) in the product description, available at https://www.signal-iduna.de/media/10612_2352007_Jan17.pdf (accessed: 26.04.2020).

12 As explained earlier, most DHP products on the German market include a death benefit for the policyholder.

13 See Art. 140 §1 VAG, first sentence.
} 
and is very restrictive on exceptions. ${ }^{14}$ Furthermore, the insurer is assumed to pursue three partially conflicting goals when allocating bonuses to the policyholders:

(a) Allocating bonuses to the policyholders who generated them after a waiting time $d$;

(b) Smoothing bonus payments over time; and

(c) Respecting the upper limit of the PPR.

For the sake of clarity, we introduce three variables $a_{t}, b_{t}, c_{t}$ that model the amount of bonus payments dictated by each of these three considerations. The allocation algorithm is given by

$$
\operatorname{Bonus}_{t+1}:=\max \left(\min \left(a_{t+1}, b_{t+1}\right), c_{t+1}\right) \quad \text { for } t \in Y \text {. }
$$

$a_{t}$ can be thought of as a default bonus-allocation rule. Taking the minimum between $a_{t}$ and $b_{t}$ ensures that a sudden decline of inflows to the PPR only gradually translates into a decline in the bonuses paid. Taking the maximum between the latter and $c_{t}$ guarantees that the insurer will not be fined for violating the provisions concerning the legal maximum amount of the PPR. ${ }^{15}$ We model bonus allocation as taking place at the beginning of each year. Therefore, the bonuses resulting from considerations in a year ending in $t \in Y$ become apparent in period $t+1, t \in Y$. For the three following considerations, define

$$
\eta_{t+1}^{j}=\frac{\mathrm{PR}_{t}^{j}}{\mathrm{PR}_{t}^{\mathrm{TDA}}+\mathrm{PR}_{t}^{\mathrm{DHP}}} \text { for } t \epsilon Y \text { and } j \epsilon\{\mathrm{TDA}, \mathrm{DHP}\}
$$

as the weight given to TDA and DHP policyholders for the bonus allocation. ${ }^{16}$

\section{Allocating bonuses to the policyholders who generated them}

According to Art.153 $\$ 2 \mathrm{VVG}$, bonuses must be allocated to the policyholders who generated them. Thus, the insurer will adapt the bonuses in a given year to the inflow of surpluses generated by the policyholders' contracts $d$ years earlier. Thereby, $d$, a positive integer, is a waiting time used to strike a balance between allocating bonuses to those who helped generate them and assuring that the PPR is not empty and thus unable to fulfil its smoothing function. In the years preceding year $d$, we assume that the yearly inflow to the PPR was $\frac{\mathrm{PPR}_{0}}{d}$. These considerations are formally specified in Eq. (33), with $j \in\{$ TDA, DHP $\}$.

$$
a_{t+1}^{j}:= \begin{cases}\eta_{t+1}^{j} \cdot \mathrm{NIS}_{t-12 d}^{\mathrm{yearly}}+\mathrm{NRR}_{t-12 d}^{j} & \text { for } t \epsilon Y, t>12 d \\ \eta_{t+1}^{j} \cdot \frac{\mathrm{PPR}_{0}}{d} & \text { for } t \epsilon Y, t \leq 12 d .\end{cases}
$$

\footnotetext{
14 See Art.140 §1, second and following sentences in conjunction with Art.140 §2 VAG.

15 See Art. $21 \S 2 \mathrm{KStG}$ in conjunction with Art. $34 \S 8,1$. KStG.

16 Signal Iduna uses this weighting method for its DHP SIGGI, see Art.5 $\$ 2$ c) of the product description available at https://www.signal-iduna.de/media/10612_2352007_Jan17.pdf (accessed: 26.04.2020).
} 
Remember that the DHP includes a death benefit and therefore $\mathrm{NRR}_{t}^{\mathrm{DHP}}:=0$ for all $t$.

\section{Smoothing bonus payments over time}

The PPR is intended to smooth possible fluctuations of the surpluses, for example in years of exceptionally high (or low) death rates or unexpected interest rate chutes. With Eq. (34) and the minimum condition in Eq. (31), we make sure that a sudden decline of inflows to the PPR only gradually translates into a decline of bonuses allocated.

$$
b_{t+1}^{j}:=\eta_{t+1}^{j} \cdot \frac{\mathrm{PPR}_{t}}{d} \text { for } t \epsilon Y \text { and } j \epsilon\{\mathrm{TDA}, \mathrm{DHP}\}
$$

\section{Respecting the upper limit of the PPR}

Finally, German law caps the PPR. ${ }^{17}$ If it exceeds the sum of the inflows of the current year plus the preceding four years, the insurer must pay taxes on the exceeding amount. ${ }^{18}$ Hence, the insurer will try to keep the PPR below this threshold. Starting from year 5 and for $t \in Y$, this can be formally expressed by

$$
\begin{aligned}
\operatorname{PPR}_{t+1} & \left.=\operatorname{PPR}_{(t+1)-12}-\text { Bonus }_{t+1}^{\mathrm{TDA}}+\operatorname{Bonus}_{t+1}^{\mathrm{DHP}}\right) \stackrel{!}{\leq} \sum_{k=0}^{4} \operatorname{Inflow}_{t-12 k}^{\mathrm{PPR}} \\
& \Longleftrightarrow \text { Bonus }_{t+1}^{\mathrm{TDA}}+\text { Bonus }_{t+1}^{\mathrm{DHP}} \geq \operatorname{PPR}_{(t+1)-12}-\sum_{k=0}^{4} \text { Inflow }_{t-12 k}^{\mathrm{PPR}}
\end{aligned}
$$

with Inflow ${ }_{t-12 k}^{\text {PPR }}$ corresponding to the inflows from Eq. (25). We then define

$$
\begin{aligned}
c_{t+1}^{j}: & =\eta_{t+1}^{j} \cdot\left(\operatorname{PPR}_{(t+1)-12}-\sum_{k=0}^{4} \text { Inflow }_{t-12 k}^{\text {PPR }}\right) \\
& \times \text { for } t \epsilon\{1,2, \ldots, 30\} \text { and } j \in\{\text { TDA, DHP }\}
\end{aligned}
$$

Now, Inequality (35) holds, as long as bonuses are bigger than $c_{t+1}:=c_{t+1}^{\mathrm{TDA}}+c_{t+1}^{\mathrm{DHP}}$, thus completing Eq. (31).

\section{Awarding of bonuses}

DHP policyholders obtain their bonus payment based on Eq. (18). For TDA policyholders, the bonus is treated as a single premium for a new TDA to the benefit of the policyholder who helped generate the bonus, thus increasing the "end-of-contract"

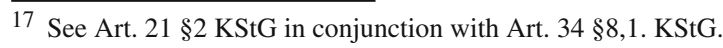

18 See Art. $21 \S 1,1 . \mathrm{KStG}$. 
lump-sum payment $\mathrm{LSP}_{t+1}$. We assume the new contract's duration to be equal to the remaining duration of the policyholder's original policy. Therefore,

$$
\operatorname{LSP}_{t+1}=\operatorname{LSP}_{t}+\frac{\operatorname{Bonus}_{t+1}^{\mathrm{TDA}}}{L_{t+1}^{\mathrm{TDA}}} \cdot \frac{D_{h+(t+1) / 12}}{D_{h+n}} \text { for } t \epsilon Y .
$$

Remember that $\mathrm{LSP}_{t}$ describes a payment due at contract termination and not in period $t$. For the PR needed for the TDA policies, this entails

$$
\mathrm{PR}_{t+1}^{\mathrm{TDA}}= \begin{cases}\mathrm{LSP}_{t+1} \cdot L_{t+1}^{\mathrm{TDA}} \cdot \frac{D_{h+n}}{D_{h+(t+1) / 12}} & \text { for } t \epsilon Y \\ \mathrm{PR}_{t}^{\mathrm{TDA}} \cdot \sqrt[12]{1+i_{G}} & \text { otherwise }\end{cases}
$$

\section{Simulation study}

\subsection{Input parameters}

The input parameters for the model are displayed in Table 4 and are intended to represent a German life insurance company after the introduction of DHP in 2007. The maximum loss of the GF $\lambda$ and the management fees $v$ are taken from Kochanski and Karnarski (2011) whose model of the DHP inspired us. The drift parameters $\mu^{\mathrm{GF}}, \mu^{\mathrm{EF}}$ and the volatility parameters $\sigma^{\mathrm{GF}}, \sigma^{\mathrm{EF}}$ are adaptations to the values proposed by Kochanski and Karnarski (2011), taking into account different long-term interest rates and differing levels of risk and upward potential for GF and EF. Taking two correlated GBMs instead of one is a deliberate decision that in our view is closer to the actual investment praxis. A robustness check is performed on this decision. The interest rates $i_{A}^{\mathrm{lt}}, i_{A}^{\text {st }}$, and $i_{G}$ were chosen to match typical pre 2008 values. We want to stress that we assume constant interest rates and a normal yield curve. The constant interest rates (as opposed to stochastically modelled interest rates) are a modelling convenience. Since our main interest is the TDA's payout and the investments in the insurers' PR are assumed to be long term, we think that taking stochastic interest rates boils down to taking their long-term means. As for the inverted yield curve (i.e. for the case that $i_{A}^{\text {st }}>i_{A}^{\mathrm{lt}}$ ), we abstract from a scenario where TDA policyholders potentially profit from a reallocation of DHP funds into the insurer's policy reserves. However, since an inverted yield curve is an exceptional event that does not necessarily accompany a shift of DHP funds, we are confident that we capture the essential long-run dynamics despite leaving it out of the model. We model a homogeneous cohort of policyholders aged $h=37$ at the conclusion of the contract. All products are bought for the same single premium $\mathrm{SP}=100$ and have the same contract duration $n=30$. Like in Bohnert et al. (2014), the guaranteed benefit of the DHP is equal to the single premium paid by policyholders. The ratio of DHP policies to TDA policies is $1 / 2$ but is varied during our analysis. The equity capital $\left(\mathrm{EC}_{0}^{\mathrm{st}}+\mathrm{EC}_{0}^{\mathrm{lt}}\right)$ and the initial provision for premium refunds $\mathrm{PPR}_{0}$ are $1.5 \%$ and $7.8 \%$ of the balance sum, respectively, thus matching the ratio over all German life insurers in 2007 according to the primary insurers' statistics by the Federal Financial Supervisory Authority ("Erstversicherungsstatistik 
Table 4 Input parameters

\begin{tabular}{|c|c|c|}
\hline Input parameter & Value & Description \\
\hline $\mathrm{N}$ & 10,000 & Number of Monte Carlo paths \\
\hline$\lambda$ & 0.2 & Maximum loss of GF (in per cent) \\
\hline$\mu^{\mathrm{GF}}$ & 0.0 .5 & Drift coefficient of GF \\
\hline$\mu^{\mathrm{EF}}$ & 0.0 .7 & Drift coefficient of GF \\
\hline$\sigma^{\mathrm{GF}}$ & 0.2 & Volatility coefficient of GF \\
\hline$\sigma^{\mathrm{GF}}$ & 0.25 & Volatility coefficient of EF \\
\hline$\rho$ & 0.7 & $\begin{array}{l}\text { Correlation of the Wiener processes from } \\
\text { Eqs. (14) and (15) }\end{array}$ \\
\hline$v$ & 0.01 & Management fees for both GF and $\mathrm{EF}$ \\
\hline$h$ & 37 & $\begin{array}{l}\text { Age of policyholder at conclusion of } \\
\text { contract }\end{array}$ \\
\hline$n$ & 30 & Contract duration \\
\hline$L_{0}^{\mathrm{TDA}}$ & 10,000 & Number of TDA policyholders in $t=0$ \\
\hline $\mathrm{SP}^{\mathrm{TDA}}$ & 100 & Single premium of TDA policy \\
\hline$L_{0}^{\mathrm{DHP}}$ & 5000 & Number of DHP policyholders in $t=0$ \\
\hline $\mathrm{SP}^{\mathrm{DHP}}$ & 100 & Single premium for DHP policy \\
\hline$x$ & $100 \%$ & $\begin{array}{l}\text { Guaranteed benefit of DHP policy } \cdot \\
\text { (single premium for DHP policy) }^{-1}\end{array}$ \\
\hline$i_{G}$ & $2.75 \%$ & Actuarial interest rate \\
\hline$i_{A}^{\mathrm{lt}}$ & $3.25 \%$ & Long-term interest rate on assets \\
\hline$i_{A}^{\mathrm{st}}$ & $0.0 \%$ & Short-term interest rate on assets \\
\hline$\delta$ & $3.25 \%$ & Dividend \\
\hline$d$ & 5 & Waiting time \\
\hline$\Theta$ & 0.05 & Cost of liquidating long-term assets \\
\hline $\mathrm{PPR}_{0}$ & $7.8 \%$ of liability sum & Initial endowment PPR \\
\hline $\mathrm{EC}_{0}^{\mathrm{st}}$ & $i_{G} \cdot x \cdot \mathrm{SP}^{\mathrm{DHP}} \cdot L_{0}^{\mathrm{DHP}}$ & Initial value of liquidity cushion \\
\hline $\mathrm{EC}_{0}^{\mathrm{st}}+\mathrm{EC}_{0}^{\mathrm{lt}}$ & $1.5 \%$ of liability sum & Initial value of total equity capital \\
\hline
\end{tabular}

der BaFin"). A yearly dividend $\delta$ is paid out to the shareholders. For simplicity, we assume the dividend to be equal to the long-term interest rate $i_{A}^{\text {lt }}$. The waiting time parameter $d$ is set to 5. This reflects the insurer's choice to maximise the funds in the PPR. Furthermore, we decided to make the liquidation of long-term assets costly. The parameter $\Theta$ makes this assumption explicit and is set to $\Theta=0.05$.

\subsection{Numerical results}

This section presents the results obtained via our Monte Carlo simulation. We first illustrate the interaction mechanism using three exemplary paths from our simulation with standard parameters. Second, we discuss the influence of the initial number of DHP contracts $N_{0}^{\mathrm{DHP}}$ on the surplus participation of the TDA policyholders. Third, 
we provide some sensitivity analysis of our results by performing robustness checks on input parameters. An overview of some variables that are not core to our analysis is given in Table 6 in "Appendix". Figure 3 shows three developments in the account value of the DHP and its decomposition over time in three different scenarios: one scenario corresponds to the median account value of the DHP as well as a good and a bad scenario (corresponding to the paths closest to the $95 \%$ and $5 \%$ quantiles of the DHP's account value).

The starting allocation per individual contract in $t=0$ is computed by the management decision function and given by $\mathrm{PR}_{0}^{\mathrm{DHP} \text {, Ind }}=0, \mathrm{GF}_{0}^{\mathrm{Ind}}=55.4$, and $\mathrm{EF}_{0}^{\mathrm{Ind}}=44.6$. In subfigures (a) and (b) of Fig. 3, we see two scenarios in which the GF's and EF's development is good enough to sustain the DHP without funds being shifted to the insurer's PR. The payout of roughly 300 and 150 in the $95 \%$ quantile path and the median path, respectively, is not a brilliant performance compared to a payout of more than 250 (without surplus participation) for the TDA. However, given that, unlike the TDA the DHP contains a death benefit equal to the account value at the time of death, this extra guarantee needs to be taken into account when comparing product performance. This is beyond the scope of this article.

Shifting our attention to the in- and outflow to the PPR and thus to the stage of the interaction, Figs. 3, 4, and 5 show that the bonus payments vary significantly from the benchmark case if DHP funds are shifted to the insurer's policy reserves. In path (c), bonuses to TDA policyholders drop to a quarter of the benchmark bonus payments in the worst years and stay low as long as DHP funds remain in the PR. This is not compensated by the higher bonus payments occurring in years 5 and 13 . The spike in year 5 (common to all paths) is caused by lower inflows to the PPR in the first five years. To avoid a PPR that is higher than the last five inflows to it (see Eq. (35)), the insurer has to pay out a bigger bonus than in the benchmark case. The spike in year 13 is caused by the sudden drop in PPR inflows in the same years, dramatically lowering the sum of the PPR inflows of the last five years. Again, the insurer awards a big bonus in order to keep the PPR below its legal cap. Note that the PPR inflows and the bonuses are below the benchmark value, even if no DHP funds are shifted to the $\mathrm{PR}$. This phenomenon is readily explained by the lower interest gains caused by the presence of a buffer invested in short-term assets. Equation (26) shows that while in the benchmark case, $A^{\text {st }}=0$, the insurer's interest gains are smaller as soon as $N^{\mathrm{DHP}}>0$ and therewith $A^{\text {st }}>0$. Of course, this crucially depends on the assumption $i_{A}^{\text {st }}<i_{A}^{\text {lt }}$ and less so on the assumption that short-term interest is equal to zero, an assumption we make for the sake of simplicity. The presence of such a buffer is intended to capture what Bettels et al. (2011) call "liquidity risk" arising from DHP policies.

To what extent does the ratio of DHP to TDA policies drive results? We discuss this question not only for our standard parameter set but for two variations of it: one representing a wider profit margin for the enterprise $\left(i_{A}^{1 \mathrm{t}}=0.04\right.$, ceteris paribus), one representing lower interest rates, keeping the profit margin constant $\left(i_{G}=0.009\right.$, $i_{A}^{\text {lt }}=0.014$, ceteris paribus). In the following paragraphs, we measure the adverse effect on the TDA policyholders by the percentage loss of the bonus share BS of the final TDA payout so as to have an easily interpretable measure that is comparable across parameter specifications. This bonus share is the part of the final payout that comes from bonus payments reinvested in the insurer's policy reserve when taken 

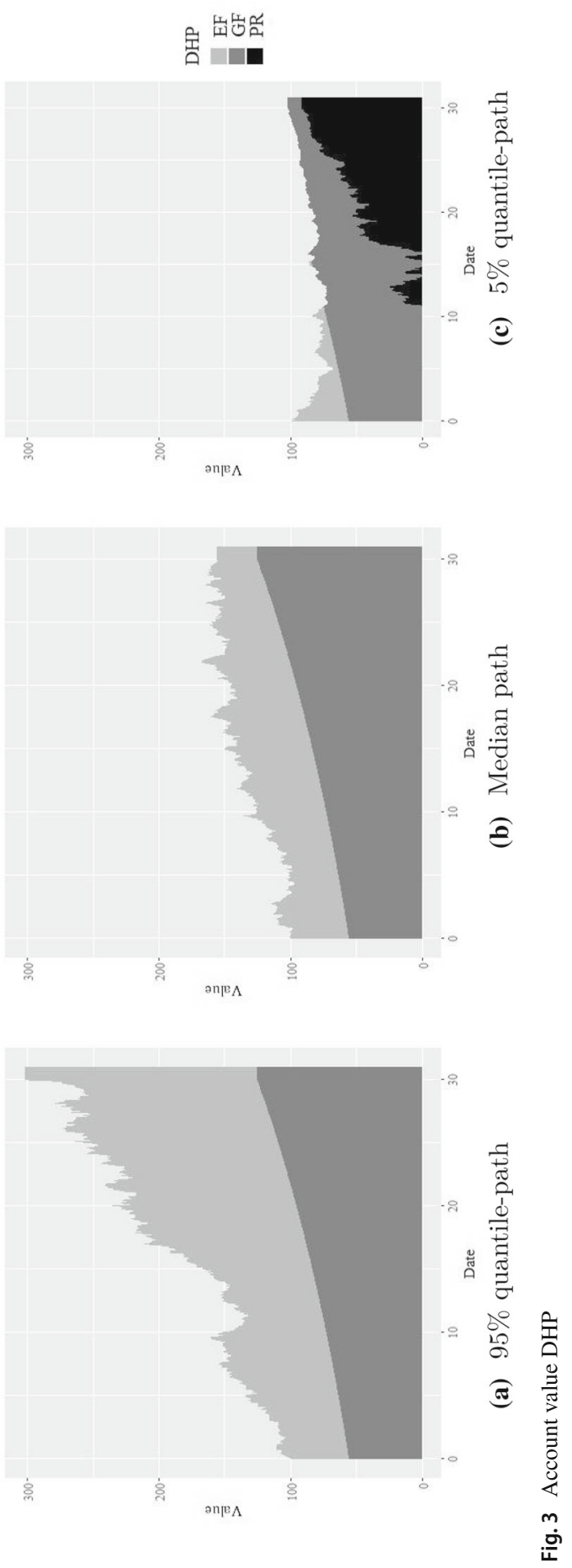

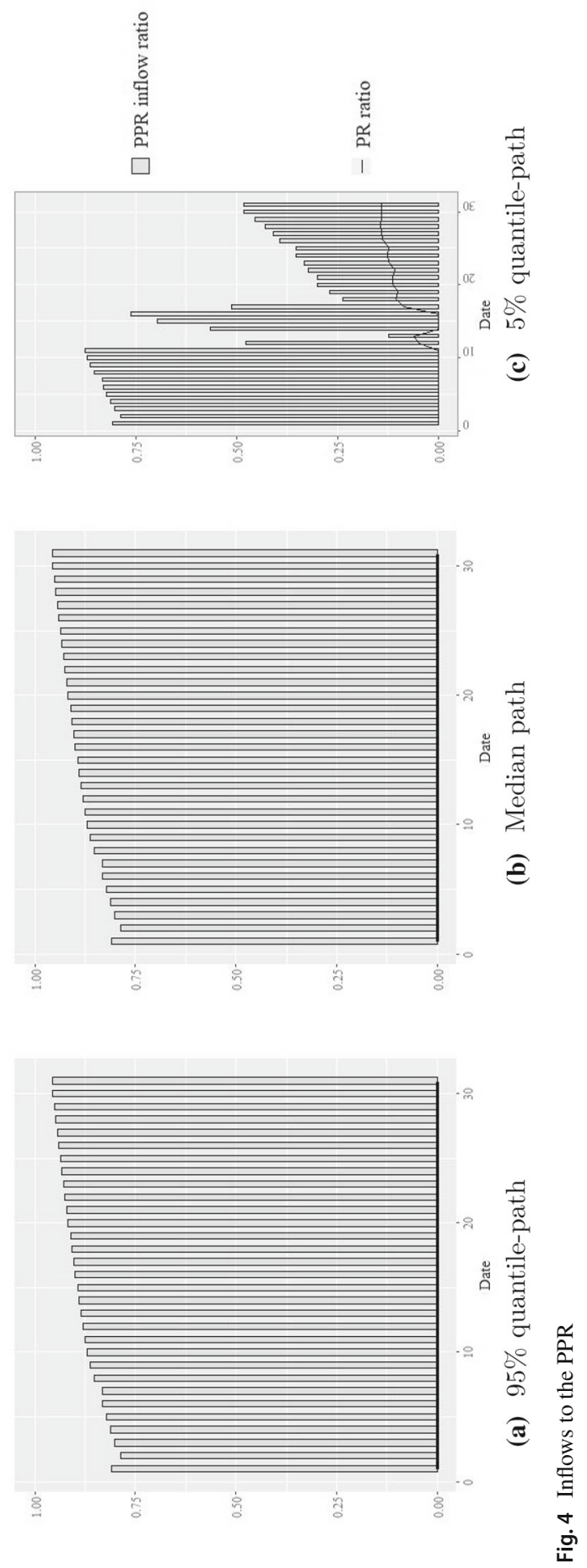

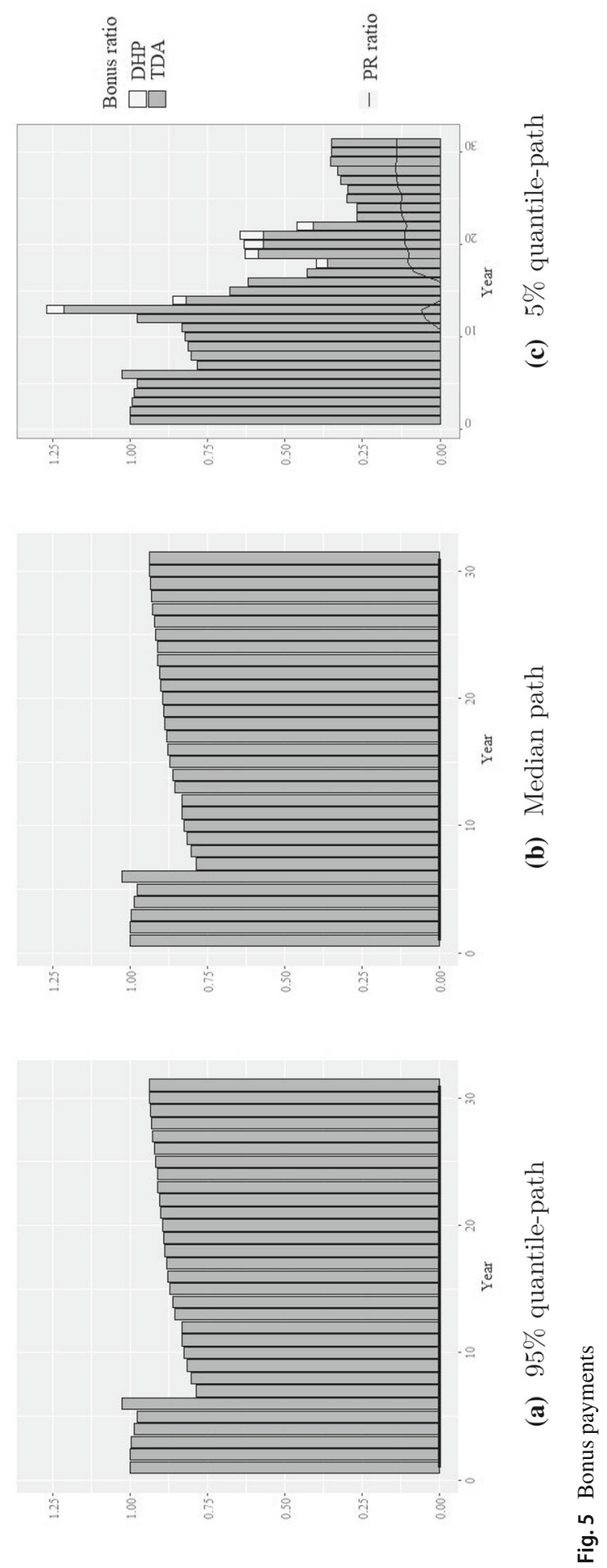
Table 5 Regression of $\Delta(\mathrm{BS})$ on $N_{0}^{\mathrm{DHP}}$

\begin{tabular}{|c|c|c|c|}
\hline & \multicolumn{3}{|c|}{$\begin{array}{l}\text { Dependent variable } \\
\Delta(\mathrm{BS})\end{array}$} \\
\hline & Standard param. & Large profit margin & Low $i_{G}$ \\
\hline$N_{0}^{\mathrm{DHP}}$ & $\begin{array}{l}-1.143 * * * \\
(0.003)\end{array}$ & $\begin{array}{l}-0.809 * * * \\
(0.004)\end{array}$ & $\begin{array}{l}-2.543 * * * \\
(0.012)\end{array}$ \\
\hline Observations & 39,993 & 40,001 & 40,001 \\
\hline$R^{2}$ & 0.735 & 0.545 & 0.519 \\
\hline
\end{tabular}

Standard errors in parentheses

$* * * p<0.01$

from the PPR. The benchmark bonus share $\overline{\mathrm{BS}}$ (calculated for each parameter set) is defined as

$$
\overline{\mathrm{BS}}:=\overline{\mathrm{LSP}}_{n}-\mathrm{SP} \cdot\left(D_{h} / D_{h+n}\right)
$$

where $\overline{\mathrm{LSP}}_{n}$ is the final LSP in the corresponding benchmark scenario (i.e. $N_{0}^{\mathrm{DHP}}=0$, all other input parameters being equal), SP is the single premium, $D$ is the number of discounted living from Eq. (5), and $h$ and $n$ are the initial age of the policyholders and the contract duration, respectively. The percentage deviation of the bonus share for any given path is defined as

$$
\Delta(\mathrm{BS}):=100 \cdot\left[\left(\mathrm{LSP}_{n}-\mathrm{SP} \cdot\left(D_{h} / D_{h+n}\right)\right)-\overline{\mathrm{BS}}\right] \cdot \overline{\mathrm{BS}}^{-1} .
$$

One general insight is common to all the three scenarios: the higher the ratio of DHP to TDA policies, the higher the mean percentage loss of the bonus share $\Delta(\mathrm{BS})$ and its variance, as shown in Fig. 6.

The results are summarised in Table 5 as results of a regression of $\Delta(\mathrm{BS})$ on $N_{0}^{\text {DHP }} .{ }^{19}$ The results can be interpreted as follows: for our standard parameter set, an increase of $N_{0}^{\mathrm{DHP}}$ of 1000 (given $N_{0}^{\mathrm{TDA}}=10,000$ ) reduces the bonus share by 1.143 percentage points as compared to $N_{0}^{\mathrm{DHP}}=0$. This effect is smaller for a bigger profit margin and bigger for lower interest rates. The variance of results increases in both cases, as indicated by the variance measure $1-R^{2}$.

A higher profit margin mitigates the negative result for the TDA. In our simulation study, this can be traced back to PPR inflows and, consequently, bonus payments being much closer to their benchmark values. This in turn can be easily understood by noticing that short-term assets, stemming from DHP funds shifted to the insurer's PR and the liquidity buffer, are relatively less important for higher long-term interest rates when calculating the net interest surplus (see Eq. (26)). Lowering the guaranteed interest rate $i_{G}$ and the long-term interest rate $i_{A}^{\text {lt }}$ drastically worsens the results for

19 The regression is performed on 10,000 observations each for $N_{0}^{\mathrm{DHP}} \epsilon\{1000,3000,5000,7000\}$ and 1 (non-stochastic) observation for $N_{0}^{\mathrm{DHP}}=0$. We removed eight insolvency cases that occurred for the standard parameter set and $N_{0}^{\mathrm{DHP}}=7000$ since our model does not include any emergency management decisions to prevent insolvency. Therefore, the results represent an upper bound. 

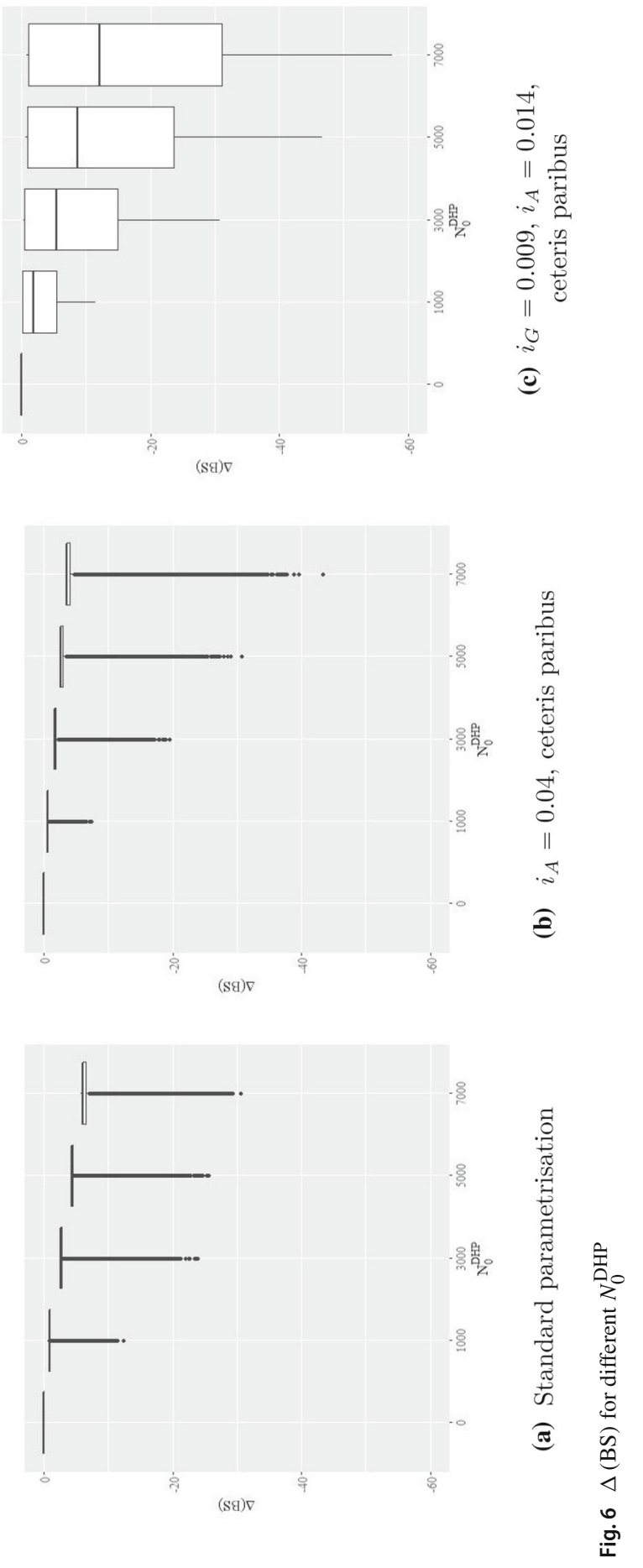
the TDA. Mirroring the effect described for higher $i_{A}^{\text {lt }}$, a lower long-term interest rate increases the influence of the liquidity cushion and the PR ${ }^{\mathrm{DHP}}$ on the net interest surplus in Eq. (26). For positive $N_{0}^{\mathrm{DHP}}$, PPR inflows and bonuses are more distant from the benchmark case $\left(N_{0}^{\mathrm{DHP}}=0\right)$. Moreover, a lower actuarial interest rate increases the amount needed in every period $t$ to ensure the guaranteed benefit $G_{t}$ of the DHP (see Eq. (22)). This influences the management decision (see Eq. (19)) and makes shifts to the insurer's PR more likely and to occur earlier than in the other scenarios. More interaction effects lead to a stronger final effect on the TDA's surplus participation. On the one hand, this should not be taken as indicative of the current real-world situation. Indeed, these days, most insurers would be glad if they could earn $1.4 \%$ interest on safe long-term investments. Furthermore, the initial values of the PPR and equity capital were set to values typical for the pre-crisis period, further complicating a transfer of the results to the present day. On the other hand, the result should urge policymakers to investigate whether the adverse effects described in this paper may have gained momentum in recent years.

The results are robust to differences in the waiting time $d$, the liquidation cost parameter $\Theta$, the dividend parameter $\delta$, and the management fees $v$. If we model the DHP's GF and EF based on one geometric Brownian motion instead of two correlated GBM, we obtain a slightly lower mean $\Delta(\mathrm{BS})$ and variance. Lowering the guaranteed benefit of the DHP to $90 \%$ instead of $100 \%$ of the single premium paid up-front as well as increasing the drift of the GF and EF mitigates the negative effects on $\Delta(\mathrm{BS})$. In line with Bettels et al. (2011), increasing the volatility of the GF and EF exacerbates the effects on $\Delta(\mathrm{BS})$ and thus increases the cost for the TDA. These last three results are consistent with the conclusion that negative interaction effects occur whenever the DHP's funds are shifted to the insurer's PR: while a lower guaranteed benefit as well as higher drifts of the funds lead to fewer instances of shifted funds, a higher volatility of the funds acts in the opposite direction. For more detail, the results of the robustness checks are displayed in Table 11 and illustrated in Fig. 7 in "Appendix".

\section{Conclusion}

This paper uses a Monte Carlo simulation to identify and quantify interaction effects between DHP and TDA policies that are detrimental to the bonus share of the latter. To do so, we model an insurance company with a detailed mechanism of surplus participation, reflecting the relevant German legal provisions and market conditions from 2007, the year DHPs were introduced in Germany. The results can be summarised by saying that losses occur when DHP funds are shifted to the insurer's policy reserve. The size of the losses depends on how often and how early these shifts occur. Given a market development that negatively affects the fund components of the DHP, low guaranteed interest rates and high guaranteed benefits favour frequent and early shifts of funds. For our standard parameter set, the results point to an additional mean loss of 1.1 percentage points of bonus share per each additional 1000 DHP policies sold (for a reference company selling 10,000 TDA). Our results support the argument made by Menzel (2008) and can be viewed as a situation where the DHP policyholders receive an option from the TDA policyholders without paying for it. Providing this option is 
costly for the TDA policyholders, even if the option is not exercised. The costs grow as soon as DHP funds are shifted.

Although the effect worsens for lower guaranteed interest rates, the results should not be directly extrapolated to the present day. A positive interest rate margin is rare these days, PPR and equity capital ratios are different, and there may have been product innovations since Kochanski and Karnarski (2011) proposed the DHP model upon which our simulation is based. Future research could focus on investigating, whether the interaction effect between TDA and DHP policies is relevant today and perhaps even exacerbated by current conditions. To do so, valuation reserves should be added to the model, since their realisation plays a bigger role in today's interest rate environment than it did in 2007. Furthermore, the DHP model may need to be adapted to product innovations. Another extension of our work would be to assess the change in shortfall risk stemming from the insurer's sale of DHP. To accomplish this, management algorithms defining emergency policies taken by the insurer should be added to the model. Last but not least, possible legal consequences of our findings should be evaluated more thoroughly: the core element of a dynamic hybrid products is its guaranteed benefit, making it a pension scheme rather than a speculative investment. The guaranteed benefit relies on the possibility of shifting the DHP's funds to the insurer's policy reserve. When this reallocation happens, TDA policyholders lose a part of their bonus share and the losses can be substantial. Whether these findings could influence portfolio transfers under $\$ 13$ VAG or raise questions regarding the equal treatment of insured persons under $\$ 138$ VAG should be the subject of further legal considerations. If legal problems arise from the sale of DHP, simply separating the investment would probably not resolve them. By jointly investing both portfolios, the interactions could be shifted to other entities such as funds. In any case, perhaps potential policyholders should be informed that the performance of a TDA they are considering buying depends on what other products their contracting partner sells.

Acknowledgements The authors would like to take this opportunity to thank Prof. E. Mammen and C. Holtorf for their valuable support. They also thank the anonymous referees for their constructive comments and suggestions.

Funding Open Access funding enabled and organized by Projekt DEAL.

Open Access This article is licensed under a Creative Commons Attribution 4.0 International License, which permits use, sharing, adaptation, distribution and reproduction in any medium or format, as long as you give appropriate credit to the original author(s) and the source, provide a link to the Creative Commons licence, and indicate if changes were made. The images or other third party material in this article are included in the article's Creative Commons licence, unless indicated otherwise in a credit line to the material. If material is not included in the article's Creative Commons licence and your intended use is not permitted by statutory regulation or exceeds the permitted use, you will need to obtain permission directly from the copyright holder. To view a copy of this licence, visit http://creativecommons.org/licenses/by/4.0/.

\section{Appendix}

\section{Summary statistics}

See Tables 6, 7, 8, and 9 . 


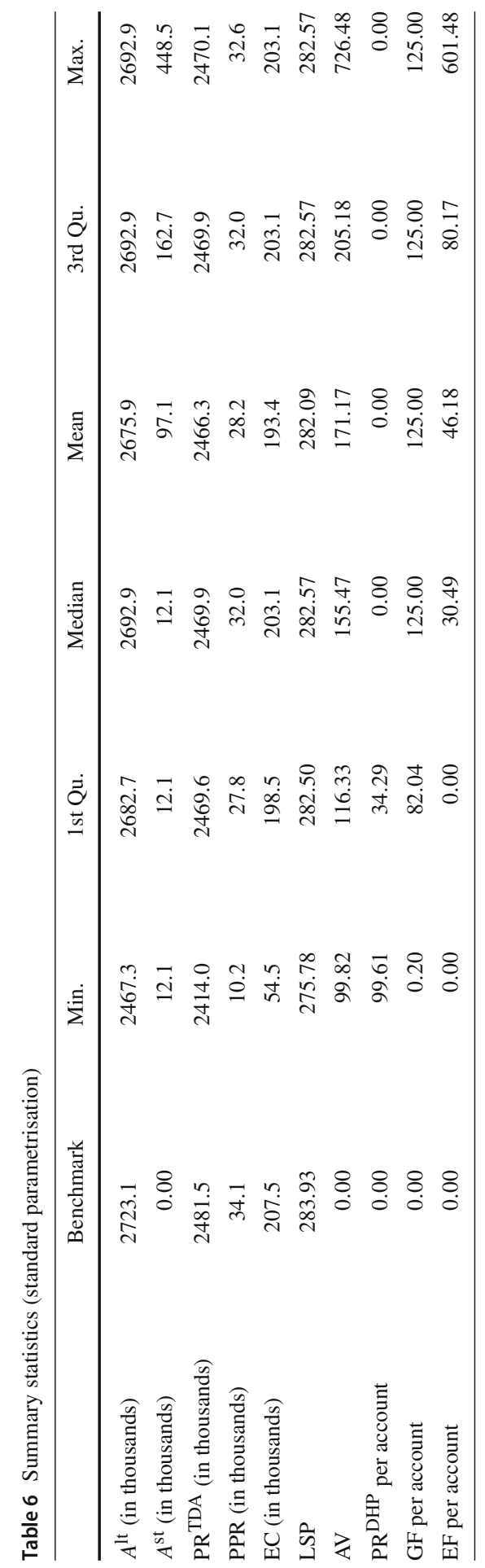




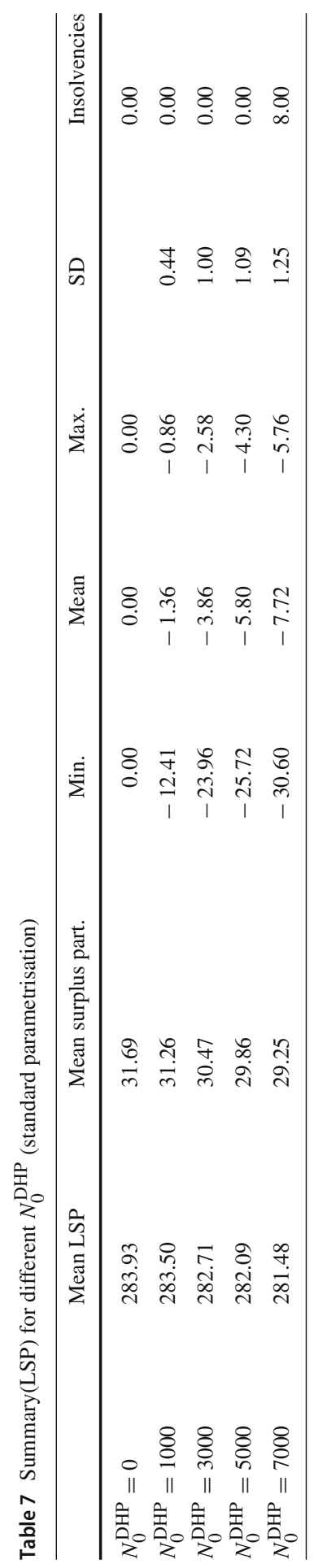




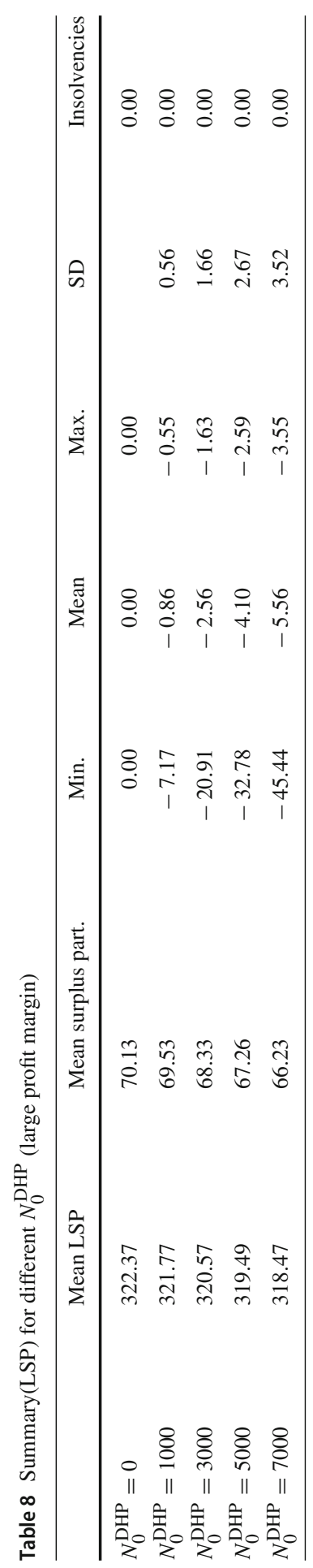




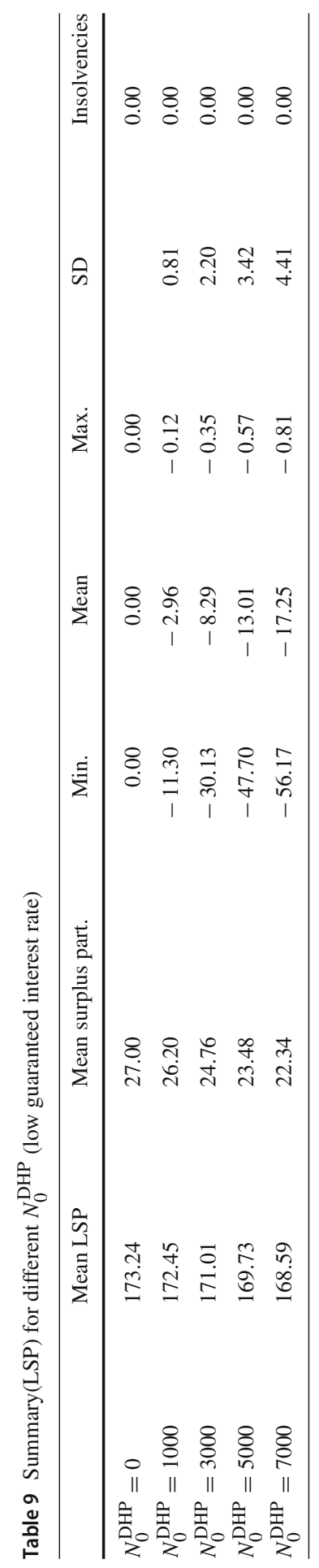




\section{Robustness checks}

See Tables 10 and 11 and Fig. 7.

Table 10 Robustness checks

\begin{tabular}{lll}
\hline Number & Description & Parameter values \\
\hline 0 & & Standard parametrisation (see table 4) \\
1 & Waiting time & $d=3$, ceteris paribus \\
2 & Liquidation cost & $\Theta=0$, c.p. \\
3 & Liquidation cost & $\delta=0.1$, c.p. \\
4 & Dividend & $\delta=0.065$, c.p. \\
5 & Dividend & $x=0.9$, c.p. \\
6 & DHP guaranteed benefit & $\rho=1, \mu^{\mathrm{EF}}=\mu^{\mathrm{GF}}=0.06, \sigma^{\mathrm{EF}}=\sigma^{\mathrm{GF}}=0.2$, c.p. \\
7 & GBM model & $\nu=0.0$ \\
8 & Management fees GF and $\mathrm{EF}$ & $\sigma^{\mathrm{GF}}=0.3, \sigma^{\mathrm{EF}}=0.35$ \\
9 & GF and EF volatilities & $\mu^{\mathrm{GF}}=0.07, \mu^{\mathrm{EF}}=0.09$ \\
10 & GF and EF drifts & \\
\hline
\end{tabular}

Table $11 \Delta$ (BS) for different robustness checks

\begin{tabular}{lllllllll}
\hline & Min. & 1st Qu. & Median & Mean & 3rd Qu. & Max. & $N$ insolvencies & SD \\
\hline Rob0 & -25.72 & -4.52 & -4.30 & -5.80 & -4.30 & -4.30 & 0 & 3.44 \\
Rob1 & -26.52 & -4.55 & -4.08 & -5.90 & -4.08 & -4.08 & 0 & 3.95 \\
Rob2 & -24.80 & -4.52 & -4.30 & -5.80 & -4.30 & -4.30 & 0 & 3.43 \\
Rob3 & -25.34 & -4.46 & -4.30 & -5.74 & -4.30 & -4.30 & 0 & 3.38 \\
Rob4 & -25.73 & -4.43 & -4.24 & -5.73 & -4.24 & -4.24 & 0 & 3.45 \\
Rob5 & -25.11 & -4.61 & -4.35 & -5.85 & -4.35 & -4.35 & 0 & 3.41 \\
Rob6 & -21.35 & -3.87 & -3.87 & -4.48 & -3.87 & -3.87 & 0 & 2.07 \\
Rob7 & -23.84 & -4.30 & -4.30 & -4.81 & -4.30 & -4.30 & 0 & 2.07 \\
Rob8 & -24.32 & -4.30 & -4.30 & -4.63 & -4.30 & -4.30 & 0 & 1.64 \\
Rob9 & -36.70 & -20.91 & -15.90 & -15.37 & -9.43 & -3.98 & 0 & 7.24 \\
Rob10 & -19.13 & -4.30 & -4.30 & -4.34 & -4.30 & -4.30 & 0 & 0.56 \\
\hline
\end{tabular}




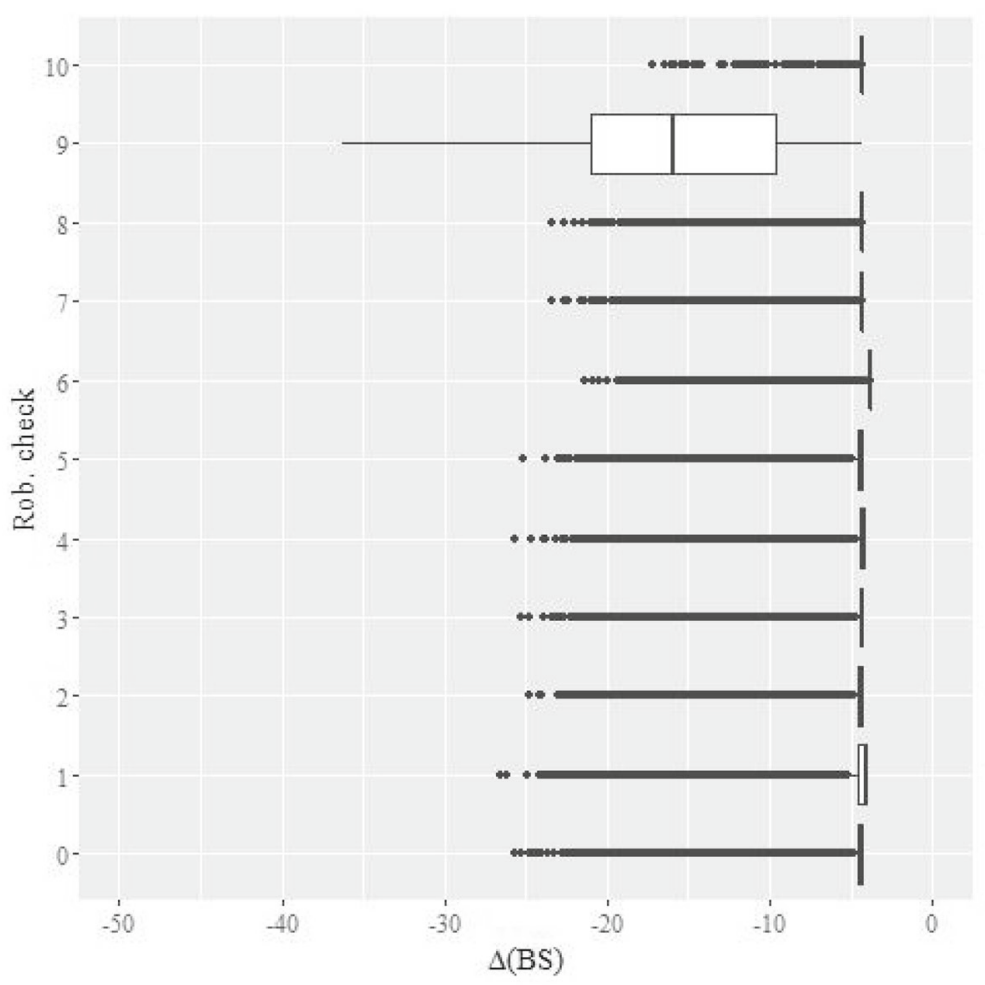

Fig. 7 Robustness checks

\section{References}

Bettels, C., Grosner, T., Leitschkis, M.: Vorsorge: Dynamische Hybride: Chancen und Risiken für Lebensversicherer. Versicherungswirtschaft 66(20), 1451-1457 (2011)

Bohnert, A.: The market of dynamic hybrid products in Germany: concept, risk-return profiles, and market overview. Zeitschrift für die gesamte Versicherungswissenschaft 102(5), 555-575 (2013)

Bohnert, A., Gatzert, N.: Fair valuation and risk assessment of dynamic hybrid products in life insurance: a portfolio consideration. Geneva Pap. Risk Insur. Issues Pract. 39(1), 148-172 (2014)

Bohnert, A., Born, P., Gatzert, N.: Dynamic hybrid products in life insurance: assessing the policyholders' viewpoint. Insur. Math. Econ. 59, 87-99 (2014)

Führer, C., Grimmer, A.: Einführung in die Lebensversicherungsmathematik. VVW GmbH, Karlsruhe (2010)

Gatzert, N., Schmeiser, H.: New life insurance financial products. In: Dionne, G. (ed.) Handbook of Insurance, pp. 1061-1095. Springer, Berlin (2013)

Hambardzumyan, H., Korn, R.: Dynamic hybrid products with guarantees—an optimal portfolio framework. Insur. Math. Econ. 84, 54-66 (2019)

Hull, J.: Options, Futures, and Other Derivatives. Prentice Hall, Pearson Education International, Upper Saddle River (2003)

Kochanski, M., Karnarski, B.: Solvency capital requirement for hybrid products. Eur. Actuar. J. 1(2), 173198 (2011)

Menzel, P.: Optionen in dynamischen Hybridprodukten. Der Aktuar 14(1), 9-12 (2008)

Ortmann, K.M.: Praktische Lebensversicherungsmathematik. Springer, Berlin (2009)

Siebert, A.: Aktuarielle Fragen zu dynamischen Hybridprodukten. Der Aktuar 14(2), 79-82 (2008) 
Publisher's Note Springer Nature remains neutral with regard to jurisdictional claims in published maps and institutional affiliations.

Nikolaj Moretti studied Mathematics, Economics, and International Relations at the universities of Heidelberg, Nottingham, Tübingen, and Dresden.

Johannes Bartels studied Mathematics with a minor in Physics in Heidelberg, where he received his doctorate in Pure Mathematics. He has been working for the German Federal Financial Supervisory Authority since 2011. On a part-time basis, he works as a lecturer for Financial and Actuarial Mathematics at the University of Heidelberg. He also worked part-time for the German Actuarial Association. 